\title{
Oxytocin Receptor (OXTR) Methylation and Cognition in Psychotic Disorders
}

\author{
Tyler B. Grove ${ }^{a} \quad$ Kyle J. Burghardt $^{\text {b }} \quad$ A. Zarina Kraal ${ }^{a}$ Ryan J. Dougherty ${ }^{d}$ \\ Stephan F. Taylor ${ }^{a, c}$ Vicki L. Ellingrod ${ }^{a, c, e}$ \\ a Department of Psychology, University of Michigan, Ann Arbor, Mich., ${ }^{b}$ Eugene Applebaum College of Pharmacy \\ and Health Sciences, Wayne State University, Detroit, Mich., 'Department of Psychiatry, University of Michigan, \\ Ann Arbor, Mich., ' Luskin School of Public Affairs, University of California, Los Angeles, Los Angeles, Calif., and \\ e College of Pharmacy, University of Michigan, Ann Arbor, Mich., USA
}

\section{Key Words}

Psychosis · Cognition · Oxytocin receptor · Methylation

\begin{abstract}
Previous reports have identified an association between cognitive impairment and genetic variation in psychotic disorders. In particular, this association may be related to abnormal regulation of genes responsible for broad cognitive functions such as the oxytocin receptor (OXTR). Within psychotic disorders, it is unknown if OXTR methylation, which can have important implications for gene regulation, is related to cognitive function. The current study examined peripheral blood OXTR methylation and general cognition in people with schizophrenia, schizoaffective disorder, and psychotic disorder not otherwise specified $(N=101)$. Using hierarchical multiple regression analysis, methylation at the Chr3:8767638 site was significantly associated with composite cognitive performance independent of demographic and medication factors while controlling for multiple testing in this combined diagnostic sample (adjusted $p=0.023$ ).
\end{abstract}

The first two authors are listed as primary.

\section{Introduction}

The neuropeptide oxytocin is associated with broad cognitive processes in humans. Previous findings indicate that both general and social cognitive processes such as working memory and facial emotion recognition, respectively, are related to oxytocin function [1-4]. Within psychotic disorders such as schizophrenia, broad cognitive deficits have been well documented [5-8], and oxytocin abnormalities may contribute to these deficits. Further, the link between social cognition and oxytocin in psychotic disorders has garnered attention due to treatment implications (e.g., intranasal oxytocin may improve facial emotion recognition) [9-11]. Recent evidence suggests that intranasal oxytocin may also improve general cognition in schizophrenia [12-15]. In addition, genetic variants of the oxytocin receptor gene (OXTR), which serves as the binding point for oxytocin action through second messenger systems in the brain, have been linked to a diagnosis of schizophrenia [16] and poorer cognitive performance in psychotic disorders $[17,18]$. Thus, the genetic regulation of oxytocin pathways via deoxyribonucleic acid (DNA) variation, and its relationship to cognition in schizophrenia continues to be an active area of research [for review, see 19]. While recent reports have

\section{KARGER}

E-Mail karger@karger.com

www.karger.com/mnp
Tyler B. Grove

Department of Psychology, University of Michigan

Ann Arbor, MI 48109 (USA)

E-Mail tylerg@umich.edu 


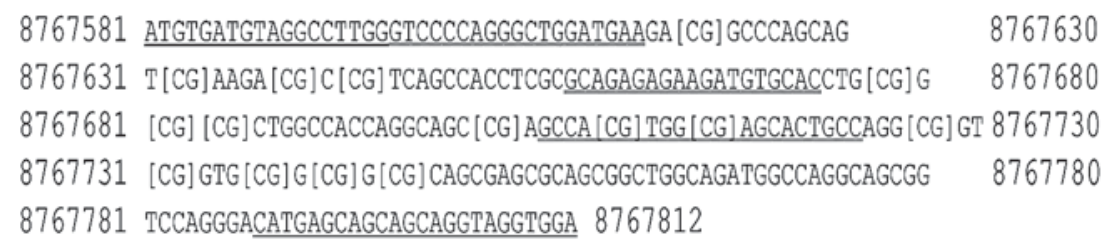

Fig. 1. Figure 1 shows the OXTR amplicon analyzed in the current study. This amplicon is contained within exon 3 of the OXTR gene downstream to the translation start site. The sequence is displayed using the GRCh38/Hg38 build coordinates Chr3:8767581 - Chr3: 87677812. The 19-nucleotide forward primer used for the amplicon is single underlined starting at 8767581 and ending at 8767599 , and the 24-nucleotide reverse primer is single underlined from

identified a relationship between increased OXTR methylation and impaired facial emotion recognition in schizophrenia [20], there have been no studies of OXTR gene regulation through DNA methylation and general cognitive performance in psychotic disorders. It is possible that oxytocin system abnormalities in psychosis may extend to OXTR methylation, and this abnormality may be related to broad cognitive deficits. If true, it would suggest that OXTR gene regulation is a potential treatment target for cognitive deficits in people with psychosis.

Therefore, the current study aimed to investigate the relationship of OXTR DNA methylation and general cognition in a sample of participants with schizophrenia, schizoaffective disorder, or psychotic disorder not otherwise specified. We hypothesized that site-specific OXTR DNA methylation would be associated with cognitive performance across participants.

\section{Methods}

\section{Participants}

Participants were recruited from the southeastern Michigan area based on the following inclusion criteria for a separate study examining the metabolic side effects of antipsychotic medications in people with a psychotic disorder: (1) Diagnostic and Statistical Manual for Mental Disorders (DSM-IV) [21] Axis I diagnosis of schizophrenia, schizoaffective disorder, schizophreniform disorder, or psychotic disorder not otherwise specified, (2) between the age of 18 and 90 , and (3) at least 6 months of stable atypical or typical antipsychotic medication dosage (atypical antipsychotics included risperidone, olanzapine, quetiapine, ziprasidone, aripiprazole, clozapine, paliperidone, iloperidone, asenapine, and lurasi-
8767789 to 8767812 . The reverse primer was ordered as the reverse complimentary primer and was biotinylated to facilitate pyrosequencing. The three sequencing primers are double underlined and found starting at positions 8767599 (19 nucleotides), 8767656 (19 nucleotides), and 8767704 (20 nucleotides). Analyzed CpG methylation sites are shown bracketed (15 total).

done; typical antipsychotics included haloperidol, fluphenazine, perphenazine, trifluoperazine, chlorpromazine, thioridazine, and thiothixene). Participants were excluded based on the following criteria: (1) diagnosed with type 2 diabetes prior to treatment with antipsychotic medications (criterion required for separate study examining metabolic side effects), and (2) active DSM-IV substance abuse diagnosis. Included participants completed a single visit to undergo a fasting blood draw, comprehensive medication history (relevant to the study of metabolic side effects), diagnostic assessment using the Structured Clinical Interview for DSM-IV (SCID-IV) [22], and cognitive testing. All evaluations were carried out by a single trained research associate. In addition, level of education and smoking history were obtained. Smoking history was assessed by asking the participants if they smoked one or more cigarettes per day. Self-report measures of depression (i.e., Beck Depression Inventory-Revised) [23], psychological stress (i.e., Psychological Stress Index) [24], and state anxiety (i.e., State-Trait Anxiety Inventory) [25] were completed to assess current mood and anxiety. Clinical assessments of current psychotic symptoms were not collected due to time limitations. All participants gave fully informed consent to participate in the protocol, as approved by the University of Michigan Institutional Review Board.

DNA Methylation Analysis

DNA was first extracted using the salt precipitation method [26] and cleaned and concentrated using commercially available kits. Five hundred nanograms of DNA was then bisulfite converted using the EZ DNA Methylation-Gold Kit (Zymo Research, Irvine, Calif., USA). Ten nanograms of bisulfite-converted DNA was placed in a touchdown PCR reaction containing OneTaq Hot Start $2 \times$ Master Mix with Standard Buffer (New England BioLabs, Ipswitch, Mass., USA) in order to amplify our chosen OXTR region of interest. Specifically, the 232-bp region is contained within the 3rd exon of the OXTR gene and covered the coordinates Chr3: 8767580 - 8767812 (using the GRCh38/hg38 build). Methylation within and immediately adjacent to this region has been investigated in several brain-based disease states [27-32]. The studied 
Table 1. Demographic, clinical, cognitive, and physiological characteristics of all clinical participants (i.e., $\mathrm{n}=101)$

\begin{tabular}{|c|c|c|}
\hline Age, years & 19 to 71 & $45.4 \pm 10.7$ \\
\hline \multicolumn{3}{|l|}{ Gender } \\
\hline Male & - & $56(55)$ \\
\hline Female & - & $45(45)$ \\
\hline \multicolumn{3}{|l|}{ Race } \\
\hline Caucasian & - & $54(53)$ \\
\hline African-American & - & $45(45)$ \\
\hline Other & - & $5(5)$ \\
\hline Level of education $(\mathrm{n}=91)$ & 1 to 8 & $3.9 \pm 1.3$ \\
\hline \multicolumn{3}{|l|}{ DSM-IV Axis I diagnosis } \\
\hline Schizophrenia & - & $32(32)$ \\
\hline Schizoaffective disorder & - & $59(58)$ \\
\hline Psychotic disorder NOS & - & $10(10)$ \\
\hline Age at diagnosis, years & 16 to 64 & $26.4 \pm 9.5$ \\
\hline Duration of illness, years & 1 to 44 & $19.0 \pm 11.3$ \\
\hline Hospitalizations, lifetime & 0 to 44 & $8.9 \pm 10.1$ \\
\hline Beck Depression Inventory-Revised $(\mathrm{n}=94)$ & 0 to 63 total & $14.95 \pm 11.29$ \\
\hline Psychological Stress Index $(\mathrm{n}=94)$ & 0 to 4 average & $2.19 \pm 0.71$ \\
\hline Social Adjustment Scores-Self-Report $(\mathrm{n}=95)$ & 0 to 5 average & $2.24 \pm 0.54$ \\
\hline BACS composite $\mathrm{z}$-score $(\mathrm{n}=94)^{\mathrm{a}}$ & -4.83 to 0.42 & $-1.92 \pm 1.06$ \\
\hline Verbal Memory & -3.85 to 1.44 & $-1.35 \pm 1.09$ \\
\hline Digit Sequencing & -5.95 to 1.66 & $-1.41 \pm 1.26$ \\
\hline Token Motor Task $(\mathrm{n}=99)$ & -5.48 to 1.43 & $-1.61 \pm 1.24$ \\
\hline Verbal Fluency & -4.14 to 1.07 & $-1.06 \pm 0.91$ \\
\hline Symbol Coding $(\mathrm{n}=98)$ & -3.97 to 0.72 & $-1.56 \pm 0.93$ \\
\hline Tower of London $(\mathrm{n}=96)$ & -4.29 to 1.36 & $-1.19 \pm 1.29$ \\
\hline Current cigarette smoker & - & $52(51.5)$ \\
\hline Packs of cigarettes per year & 37 to 1,095 & $86.8 \pm 123.0$ \\
\hline Atypical antipsychotic & - & $91(90)$ \\
\hline Typical antipsychotic & - & $19(18.8)$ \\
\hline Daily chlorpromazine equivalents, mg & 25 to 3,175 & $530.6 \pm 517.9$ \\
\hline
\end{tabular}

Note: data are presented as range, mean $\pm \mathrm{SD}$, or $\mathrm{n}(\%)$. NOS $=$ Not otherwise specified. ${ }^{\text {a }}$ Computation of BACS z-scores utilized a healthy control comparison group.

region is contained within a CpG Island of the OXTR gene that spans from approximately 20 to $2,350 \mathrm{bp}$ downstream of the transcription start site. Differential methylation of this $\mathrm{CpG}$ region has been shown to have large functional effects on OXTR expression $[30,33]$. Within our target amplicon, 15 CpG methylation sites were chosen for analysis by the method of pyrosequencing using three separate pyrosequencing primers for the amplicon [34]. Other CpG methylation sites within the amplicon were not included for the following reasons: (1) the assay design for the region was not included (dictated by the software), and (2) a detectable methylation value was not replicated in $\geq 66 \%$ of the sample. Methylation calls for individual samples were excluded if the replication methylation value was too variable (defined as a coefficient of variation $>2.5 \%$ ) and thus deemed unreliable. The 15 methylation calls that were included for analysis were normalized using the method of Goodrich et al. [35]. Briefly, this method uses methylation standards $(0,20,40,60,80$, and $100 \%$ methylated) for each analysis in order to construct a standardized curve on which each sample is normalized. Figure 1 shows the amplicon region, primers used, and methylation sites analyzed. All primers were designed using the Pyromark AssayDesgin 2.0 software.

\section{Cognition}

Cognitive performance was determined using the Brief Assessment of Cognition in Schizophrenia (BACS), a performance-based battery of cognition with six subscale scores, including Verbal Memory, Digit Sequencing (working memory), Token Motor Task (motor speed), Verbal Fluency, Symbol Coding (attention and speed of information processing), and Tower of London (executive functions) [36, 37]. In order to standardize and interpret BACS performance, $z$-scores were computed with reference to a sample of healthy controls who also lived in Southeastern Michigan $(n=$ 63) and are described in Grove et al. [38]. The BACS provides a composite score to describe overall cognitive performance. This 
Table 2. Nontransformed methylation of OXTR sites

\begin{tabular}{llll}
\hline No. & Site & $\mathrm{n}$ & Mean \pm SD \\
\hline 1 & Chr 3:8767620 & 91 & $17.3 \pm 8.2$ \\
2 & Chr 3:8767632 & 89 & $23.9 \pm 10.8$ \\
3 & Chr 3:8767638 & 80 & $17.3 \pm 8.8$ \\
4 & Chr 3:8767641 & 77 & $20.4 \pm 13.1$ \\
5 & Chr 3:8767678 & 91 & $21.9 \pm 7.7$ \\
6 & Chr 3:8767681 & 92 & $17.6 \pm 8.1$ \\
7 & Chr 3:8767683 & 88 & $12.3 \pm 7.1$ \\
8 & Chr 3:8767701 & 85 & $21.3 \pm 8.7$ \\
9 & Chr 3:8767708 & 68 & $11.1 \pm 4.8$ \\
10 & Chr 3:8767713 & 67 & $21.4 \pm 9.4$ \\
11 & Chr 3:8767727 & 91 & $20.6 \pm 9.9$ \\
12 & Chr 3:8767731 & 89 & $14.6 \pm 9.5$ \\
13 & Chr 3:8767736 & 90 & $20.6 \pm 13.0$ \\
14 & Chr 3:8767739 & 80 & $19.7 \pm 13.2$ \\
15 & Chr 3:8767742 & 81 & $13.0 \pm 6.8$ \\
\hline Overall & - & 92 & $18.2 \pm 5.9$ \\
methylation & & & \\
\hline
\end{tabular}

Note: chromosomal locations using Human Genome build 38.

score is analyzed in a 'whole model' approach where, in the current study, a significant relationship between BACS composite score and methylation site warrants further analysis of the subscale scores.

\section{Statistical Analyses}

Demographic and clinical characteristics are described by means with standard deviation. Differences between the healthy control sample (used to compute BACS $z$-scores) and participants with a psychotic disorder were determined using independent samples $t$-tests or $\chi^{2}$ analyses. The healthy controls did not have methylation data available and were not included in methylation analyses. Pearson correlational analyses were used to identify significant associations between BACS $z$-scores (composite score first and then followed by subscale scores if necessary) and methylation sites. Hierarchical multiple regression models were used to determine if a specific OXTR methylation site (i.e., identified from significant Pearson correlational analyses) would be associated with BACS composite $z$-scores independent of variables related to cognition and methylation. The regression models contained two steps. The first step included level of education, with a ranking of 1 (grade 6 or less) to 8 (completed graduate/professional school), as educational attainment has been consistently associated with cognition in schizophrenia $[39,40]$. In addition, considering that epigenetics can be mediated by antipsychotic medication type (i.e., atypical or typical) and cigarette smoking, both of which may play an important role in the pathophysiology of schizophrenia [41-43], antipsychotic type and cigarette smoking status (current smoker or nonsmoker) were also included as independent variables in the first step of the models. A methylation site that significantly correlated with BACS composite $z$-score was entered as an independent variable in the second and final step of the models. Within all models, standardized betas are reported, along with p values for the amount of variance in the BACS z-score explained by the individual methylation site compared with demographic and medication variables. These values were corrected using Benjamini and Hochberg's False Discovery Rate (threshold of 0.05) [44-46], which has been recommended as an alternative to the conservative Bonferroni correction for clinical studies. In addition, due to the nonnormal distribution of methylation data, all methylation results were log transformed for statistical analyses. While power analysis was not conducted due to the lack of previous studies examining OXTR methylation and cognition in psychotic disorders needed to estimate the effect size, the current sample size is comparable or larger than previous OXTR methylation studies of clinical populations and psychiatric symptoms [28, 29, 47-50]. JMP statistical software (SAS Institute Inc., Cary, N.C., USA) was used for all analyses.

\section{Results}

Demographic, Clinical, and Cognitive Characteristics

Demographic, clinical, and cognitive characteristics of the 101 participants with a psychotic disorder are presented in table 1. Compared to the healthy control sample used to compute BACS $z$-scores $[\mathrm{n}=63$; average age of $43.5 \pm 11.3$; age range of $19-66 ; 65 \%$ male $(n=41)$; Bachelor's degree level of education $6.1 \pm 1.8$, and $70 \%$ Caucasian $(n=46)$ ], participants with a psychotic disorder had a significantly lower level of education $[t(151)=8.71, \mathrm{p}<$ $0.0001]$ and a significantly higher ratio of non-Caucasian participants $\left(\chi^{2}=9.47, \mathrm{n}=160, \mathrm{p}=0.002\right)$.

\section{Relationships between BACS and OXTR Methylation}

The average, nontransformed values of the analyzed OXTR methylation sites are listed in table 2. Overall, the investigated sites were 'lowly' methylated (average methylation of sites $\sim 20 \%$ ), which is in agreement with healthy control studies investigating OXTR methylation within and near this region [29, 32].

A significant negative Pearson correlation was observed between Chr 3:8767638 site and BACS composite $z$-score. Neighboring methylation sites (i.e., Chr 3: 8767708, Chr 3:8767681, and Chr 3:8767632), along with the remaining methylation sites, were not significantly correlated with BACS composite $z$-score except for $\mathrm{Chr}$ 3:8767742, which was positively correlated (table 3 ).

Given the significant findings at Chr3:8767638 and Chr3:8767742, we conducted separate hierarchical regression analyses for each site. The multiple regression analyses showed that only OXTR methylation site Chr3: 8767638 explained a significant amount of variance in BACS composite $z$-score, along with Verbal Memory, Symbol Coding, and Tower of London $z$-scores, indepen- 
Table 3. Pearson correlations between BACS and log-transformed OXTR methylation

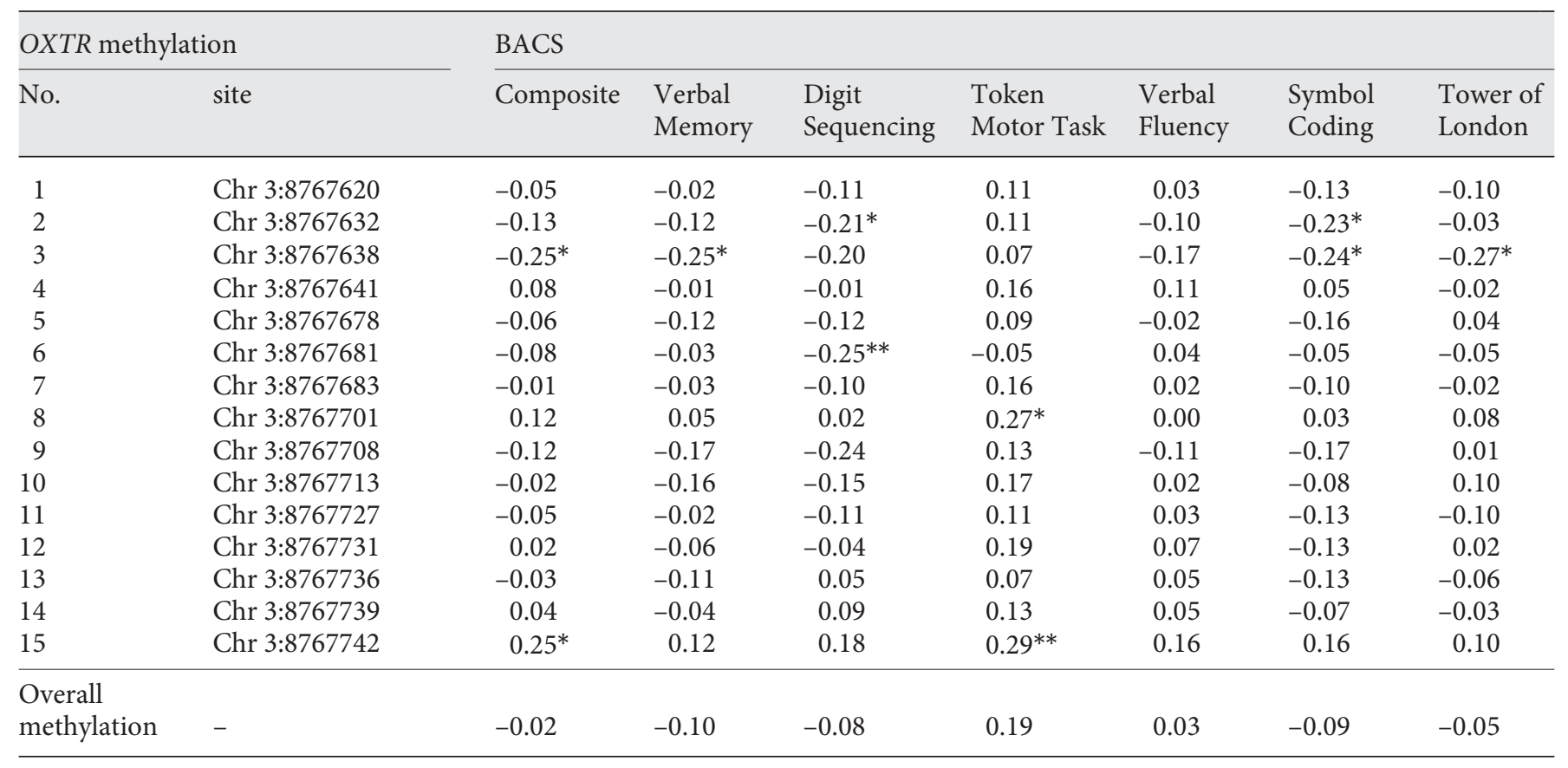

Note: Pearson correlation coefficients between the log-transformed methylation of the OXTR gene (rows) and BACS $z$-scores (columns). ${ }^{*} \mathrm{p}<0.05,{ }^{* *} \mathrm{p}<0.01$.

Table 4. Results from the hierarchical regression models used to predict the effect of Chr3:8767638 OXTR methylation on BACS performance $(n=72)$

\begin{tabular}{|c|c|c|c|c|c|c|c|c|c|}
\hline \multirow[t]{2}{*}{ BACS } & \multicolumn{5}{|l|}{ Step 1} & \multicolumn{4}{|l|}{ Step 2} \\
\hline & $\begin{array}{l}\text { level of } \\
\text { education }\end{array}$ & $\begin{array}{l}\text { antipsychotic } \\
\text { type }\end{array}$ & $\begin{array}{l}\text { current } \\
\text { smoker }\end{array}$ & $\overline{\Delta R^{2}}$ & $\Delta F$ & $\begin{array}{l}\text { variable statistics, } \beta \\
\text { Chr3:8767638 }\end{array}$ & $\Delta R^{2}$ & $\Delta F$ & $\begin{array}{l}\text { FDR- } \\
\text { adjusted } \\
\text { p value }\end{array}$ \\
\hline Composite & $0.30^{*}$ & -0.18 & 0.17 & 0.15 & $4.03^{*}$ & $-0.31^{*}$ & 0.09 & $7.89^{*}$ & 0.023 \\
\hline Token Motor Task & 0.09 & -0.14 & -0.02 & 0.03 & 0.69 & 0.00 & 0.00 & 0.00 & 0.600 \\
\hline Verbal Fluency & -0.07 & -0.01 & 0.16 & 0.03 & 0.75 & -0.21 & 0.04 & 3.00 & 0.062 \\
\hline Symbol Coding & 0.22 & 0.00 & 0.04 & 0.05 & 1.12 & $-0.27^{*}$ & 0.07 & $5.06^{*}$ & 0.029 \\
\hline Tower of London & $0.29 *$ & -0.09 & $0.25^{*}$ & 0.14 & $3.72 *$ & $-0.27^{*}$ & 0.07 & $6.04^{*}$ & 0.024 \\
\hline
\end{tabular}

Note: BACS composite and subscale $z$-scores were included as the dependent variable. Level of education, antipsychotic type (atypical or typical), and cigarette smoking status (Step 1) and methylation value (Step 2) were entered as independent variables for each model. The false discovery rate (FDR)-adjusted p values were calculated for the Step 2 variable (Chr3:8767638 site) only. Standardized betas are reported. ${ }^{*} \mathrm{p}<0.05$.

dent of level of education, antipsychotic type, and smoking status, even after correcting for multiple testing (table 4). The association between Chr3:8767742 and BACS composite $z$-score did not remain significant after ac- counting for level of education, antipsychotic type, and smoking status $\left(\Delta R^{2}=0.04, \Delta F=3.19, \beta=0.19, \mathrm{p}=0.079\right)$. Consequently, Chr3:8767742 and BACS subscale $z$-scores were not analyzed with hierarchical regression models. 


\section{Discussion}

\section{Oxytocin Methylation and Cognition}

Within the current study, a significant negative association was observed between $\mathrm{CpG}$ methylation at $\mathrm{Chr} 3$ : 8767638 in the OXTR gene and cognitive performance independent of demographic and antipsychotic medication variables in people with schizophrenia, schizoaffective disorder, or psychotic disorder not otherwise specified. Specifically, cognitive deficits in domains such as working memory, attention and speed of information processing, and executive functions may be related to peripheral abnormal OXTR DNA methylation in people with a psychotic disorder.

To our knowledge, this is the first study to investigate OXTR gene methylation and general cognition in people with a psychotic disorder. A previous study has examined facial emotion recognition in people with a psychotic disorder (at site -934 upstream of the OXTR start codon in DNA and the same CpG island as the region in the current study), and found increased OXTR methylation in females, but not males, was associated with greater difficulties identifying angry, sad, and happy faces [20]. In the current study, the association between OXTR methylation and cognition was observed independent of sex. Previous studies have also examined OXTR methylation and social cognition in psychiatrically healthy participants and found that higher degrees of OXTR methylation were associated with greater activation of the superior temporal gyrus/supramarginal gyrus and dorsal anterior cingulate cortex during an animacy task [32]. Further, increased OXTR methylation was associated with higher neural response and decreased functional coupling within brain regions supporting socioemotional processing (i.e., amygdala, fusiform, and insula) [31]. While OXTR methylation in these two studies was assessed in a neighboring region compared to the current study, the methylation regions analyzed in these studies were still contained within the same CpG Island. In conjunction, these findings suggest that decreased OXTR methylation in this CpG Island may contribute to both lower- and higher-level cognitive processing (e.g., working memory and facial emotion recognition, respectively). Yet within psychotic disorders, the relationship between the oxytocin system and cognition is inconsistent. The Psychiatric Genomic Consortium (PGC) did not identify oxytocin (OXT) or OXTR as risk factors for schizophrenia via a genomicwide association analysis [51]. However, this may be due to oxytocin pathway genes not being implicated in the susceptibility to a psychotic disorder, but rather susceptibility to impaired social behavior (i.e., emotional withdrawal) within the PGC sample [52]. In addition, the role of the oxytocin system in the pathophysiology of positive, negative, and cognitive symptoms continues to be implicated $[13,53]$.

The mechanism by which abnormal oxytocin methylation influences cognition may be explained by biological models that indicate perinatal stress disrupts the oxytocin system in brain areas associated with numerous cognitive processes (e.g., memory retrieval, decisionmaking, and social cognition) $[54,55]$. Specifically, increased methylation of OXTR may lead to abnormal gene expression that disrupts hippocampal and/or medial prefrontal cortex function and causes cognitive impairment (e.g., memory deficits and/or impaired emotion recognition) [see 56 for a review]. This disruption may be exacerbated by psychosocial stressors, which can increase OXTR methylation [28]. Considering that OXTR methylation at Chr 3:8767638 was significantly associated with working memory, processing speed, and executive functions, abnormal activation in associated areas (e.g., prefrontal cortex and related substructures) [57-61] may be linked to decreased peripheral OXTR methylation in people with a psychotic disorder. However, future neuroimaging studies with patients and healthy control populations are needed to determine this potential relationship between OXTR methylation and brain function in psychosis. Thus, while further research is needed to confirm these postulations and resolve discrepant findings, abnormal oxytocin methylation in the periphery and the brain may not only contribute to impaired socioemotional processing in psychosis [20], but also general cognitive deficits in psychotic disorders, making OXTR methylation a potential biomarker or treatment target.

Previous reports also indicate that OXTR methylation in overlapping regions of interest is associated with social anxiety disorder [29]. Specifically, elevated Chr3:8767736 methylation and reduced Chr3:8767708 methylation in participants with social anxiety disorder compared with healthy controls was observed [29]. In the current study, no significant correlations were observed between Chr3: 8767708 methylation and BACS composite or subscale scores. However, the previous report highlights the importance of OXTR methylation at individual sites, which has apparent variable methylation in association with a given phenotype and may contribute to different disease pathophysiology (i.e., psychotic disorder vs. social anxiety disorder). 
Understanding the Influence of Environmental and

Lifestyle Factors on Cognition

The potentially positive cognitive effects of nicotine obtained through cigarette smoking in schizophrenia are well documented $[62,63]$, along with the potential role for nicotinic receptors in cognition [64]. The effect of smoking on DNA methylation has been observed in several populations [65-67]. Additionally, cigarette smoking has been found to affect OXTR gene regulation and transcription in pregnant women [68]. Yet the current findings suggest smoking may not impact the associations between $O X T R$ methylation and cognition in people with a psychotic disorder, as OXTR methylation explained BACS composite variance independent of smoking status. Further, besides the environmental effect of smoking, cardiovascular function plays an important role in cognition [69-71]. Future work may investigate the methylation of known genes that contribute to cardiovascular function in schizophrenia (e.g., methylenetetrahydrofolate reductase) for their role in the relationship between cardiovascular health and cognition in psychotic disorders [72-74].

\section{Limitations}

The current study was observational in nature, and only associations can be inferred. Considering the critical need for replication of the current findings, future prospective studies could not only replicate but also expand upon the current findings by assessing coincident changes in gene methylation and cognition in psychotic disorders coupled with brain imaging during disease progression and/or treatment to explore casual relationships. While the current study used a candidate epigenetic approach and investigated a single area of a single gene, along with False Discovery Rate correction to reduce the chance of type 1 errors, few correlations were observed between cognition and gene methylation. Associations between cognition and gene methylation of other genes will need to be tested independently in future studies. Further, consequences of gene methylation through RNA studies and downstream protein levels will need to be assessed to understand the molecular effects of differential gene methylation in cognitive processes. However, as described earlier, differential methylation of the CpG Island that contained the current methylation sites has been linked to significant effects in OXTR expression and oxytocin levels [75]. A limitation of the current study is not assessing DNA methylation at the tissue of interest, which in this case would be the brain. A future study using available postmortem human brain samples could have some benefits but would not be without significant limitations of its own. Such limitations may include epigenetic changes that could occur from death to tissue processing, accurate phenotyping of subjects at the time of death (e.g., disease status, medication use, lifestyle factors, cognitive status, etc.), and choosing specific brain regions to analyze OXTR DNA methylation. The current study did not use postmortem brain samples to validate the peripheral blood findings due to a lack of sample access. However, the use of peripheral tissues to study brain genetic regulation is an important initial strategy [76-78], and previously reported correlations between OXTR methylation in peripheral blood mononuclear cells and the brain suggest that peripheral methylation may be related to brain function [79]. Additionally, the use of peripheral blood DNA methylation can have significant biomarker value regardless of it not being from the tissue of interest. Nevertheless, preclinical models of cognition in schizophrenia are available [80] and may enable translational studies that can be used to support epigenetic findings in the peripheral blood from humans.

The correlation of DNA methylation across tissues continues to be an active area of research, and correlations between OXTR peripheral blood methylation and the temporal cortex have been reported, suggesting that there may be some degree of similarity [50]. Although likely gene dependent, work in animals and humans continues to support translatability between peripheral blood and brain DNA methylation [81-84]. Nevertheless, correlating site-specific peripheral methylation findings to the brain may be required. As studies continue to assess DNA methylation in the periphery, it is important that similar extraction and assessment methodologies are used in order to test replication of any findings put forth. Finally, although limited in sample size, significant associations remained after correction for multiple testing. However, larger sample sizes with better demographically matched controls than the current study (along with cognition and methylation data for both cases and controls) may allow for replication of these analyses within and across DSM-IV diagnostic groups. Between-group analyses within the current sample are limited by the small number of participants diagnosed with psychotic disorder not otherwise specified (i.e., 10 participants). In addition, the current study did not assess psychotic symptoms, and future studies should explore the relationship between OXTR methylation and the severity of psychosis, as previous reports indicate a relationship between $O X T R$ variants and a diagnosis of schizophrenia [16]. 


\section{Conclusion}

Methylation levels of the OXTR gene at the Chr 3: 8767638 site are negatively associated with general cognitive performance in people with a psychotic disorder (i.e., schizophrenia, schizoaffective disorder, or psychotic disorder not otherwise specified). This association is independent of demographic and antipsychotic medication type, and remains after adjusting for multiple testing, suggesting that abnormal OXTR methylation may contribute to the cognitive deficits and pathophysiology of psychotic disorders.

\section{Acknowledgement}

The authors thank the staff and consumers at the Washtenaw County Health Organization, Ann Arbor Veterans Affairs Medical Center, and the Detroit-Wayne County Community Mental Health
Agency for their assistance and participation, respectively, in the current study. In addition, this study was supported by grants from The National Institute of Mental Health (R01MH082784, DK020572, and 2UL1TR000433), the National Center for Advancing Translational Sciences of the National Institutes of Health (2UL1TR000433-06), and the Chemistry Core of the Michigan Diabetes Research and Training Center (DK020572) from the National Institute of Diabetes and Digestive and Kidney Diseases. The content is solely the responsibility of the authors and does not necessarily represent the official views of the National Institutes of Health.

\section{Statement of Ethics}

The authors have no ethical conflicts to disclose.

\section{Disclosure Statement}

Stephan F. Taylor has a research contract with St. Jude Medical and receives research support from Neuronetics. All other authors declare that they have no conflicts of interest.

\section{References}

1 Kirsch P, Esslinger C, Chen Q, Mier D, Lis S, Siddhanti S, Gruppe H, Mattay VS, Gallhofer B, Meyer-Lindenberg A: Oxytocin modulates neural circuitry for social cognition and fear in humans. J Neurosci 2005;25:11489-11493.

2 Meyer-Lindenberg A, Domes G, Kirsch P, Heinrichs M: Oxytocin and vasopressin in the human brain: social neuropeptides for translational medicine. Nat Rev Neurosci 2011;12: 524-538.

3 Cochran DM, Fallon D, Hill M, Frazier JA: The role of oxytocin in psychiatric disorders: a review of biological and therapeutic research findings. Harv Rev Psychiatry 2013;21: 219-247.

4 Chini B, Leonzino M, Braida D, Sala M: Learning about oxytocin: pharmacologic and behavioral issues. Biol Psychiatry 2014;76: 360-366.

5 Keefe RS: The longitudinal course of cognitive impairment in schizophrenia: an examination of data from premorbid through posttreatment phases of illness. J Clin Psychiatry 2014;75(suppl 2):8-13.

6 Nuechterlein KH, Ventura J, Subotnik KL, Bartzokis G: The early longitudinal course of cognitive deficits in schizophrenia. J Clin Psychiatry 2014;75(suppl 2):25-29.

7 Kurtz MM: Neurocognitive impairment across the lifespan in schizophrenia: an update. Schizophr Res 2005;74:15-26.

8 Stirling J: Neurocognitive function and outcome in first-episode schizophrenia: a 10year follow-up of an epidemiological cohort. Schizophr Res 2003;65:75-86.
9 Woolley JD, Chuang B, Lam O, Lai W, O'Donovan A, Rankin KP, Mathalon DH, Vinogradov S: Oxytocin administration enhances controlled social cognition in patients with schizophrenia. Psychoneuroendocrinology 2014;47:116-125.

10 Averbeck BB, Bobin T, Evans S, Shergill SS: Emotion recognition and oxytocin in patients with schizophrenia. Psychol Med 2011:1-8.

11 Davis MC, Lee J, Horan WP, Clarke AD, McGee MR, Green MF, Marder SR: Effects of single dose intranasal oxytocin on social cognition in schizophrenia. Schizophr Res 2013; 147:393-397.

12 Feifel D, Macdonald K, Cobb P, Minassian A: Adjunctive intranasal oxytocin improves verbal memory in people with schizophrenia. Schizophr Res 2012;139:207-210.

13 Feifel D, Shilling PD, MacDonald K: A review of oxytocin's effects on the positive, negative, and cognitive domains of schizophrenia. Biol Psychiatry 2016;79:222-233.

14 Bakermans-Kranenburg MJ, van I Jzendoorn MH: Sniffing around oxytocin: review and meta-analyses of trials in healthy and clinical groups with implications for pharmacotherapy. Transl Psychiatry 2013;3:e258.

15 Michalopoulou PG, Averbeck BB, Kalpakidou AK, Evans S, Bobin T, Kapur S, Shergill SS: The effects of a single dose of oxytocin on working memory in schizophrenia. Schizophr Res 2015;162:62-63.

16 Montag C, Brockmann EM, Bayerl M, Rujescu D, Muller DJ, Gallinat J: Oxytocin and oxytocin receptor gene polymorphisms and risk for schizophrenia: a case-control study. World J Biol Psychiatry 2013;14:500-508.
17 Davis MC, Horan WP, Nurmi EL, Rizzo S, Li W, Sugar CA, Green MF: Associations between oxytocin receptor genotypes and social cognitive performance in individuals with schizophrenia. Schizophr Res 2014;159:353357.

18 Schmidt SJ, Mueller DR, Roder V: Social cognition as a mediator variable between neurocognition and functional outcome in schizophrenia: empirical review and new results by structural equation modeling. Schizophr Bull 2011;37(suppl 2):S41-S54.

19 Bartholomeusz CF, Ganella EP, Labuschagne I, Bousman C, Pantelis C: Effects of oxytocin and genetic variants on brain and behaviour: implications for treatment in schizophrenia. Schizophr Res 2015;168:614-627.

20 Rubin LH, Connelly JJ, Reilly JL, Carter CS, Drogos LL, Pournajafi-Nazarloo H, Ruocco AC, Keedy SK, Matthew I, Tandon N, Pearlson GD, Clementz BA, Tamminga CA, Gershon ES, Keshavan MS, Bishop JR, Sweeney JA: Sex and diagnosis specific associations between DNA methylation of the oxytocin receptor gene with emotion processing and temporal-limbic and prefrontal brain volumes in psychotic disorders. Biol Psychiatry 2016;1:141-151.

21 American Psychiatric Association: Diagnostic and Statistical Manual of Mental Disorders, ed 4. Washington, American Psychiatric Association, 2000.

22 First MB, Spitzer RL, Gibbon M, Williams JBW: Structured Clinical Interview for DSMIV Axis I Disorders SCID-I: Clinician Version, Administration Booklet. Washington, American Psychiatric Press, 1997. 
23 Beck AT, Steer RA: Manual for the Beck Depression Inventory, 1993 edition. San Antonio, The Psychological Corporation, 1987.

24 Tso IF, Grove TB, Taylor SF: Self-assessment of psychological stress in schizophrenia: preliminary evidence of reliability and validity. Psychiatry Res 2012;195:39-44.

25 Spielberger CD, Gorsuch RL, Lushene R, Vagg PR, Jacobs GA: Manual for the StateTrait Anxiety Inventory. Palo Alto, Consulting Psychologists Press, 1983.

26 Lahiri DK, Nurnberger JI Jr: A rapid non-enzymatic method for the preparation of HMW DNA from blood for RFLP studies. Nucleic Acids Res 1991;19:5444.

27 Mamrut S, Harony H, Sood R, Shahar-Gold $\mathrm{H}$, Gainer H, Shi YJ, Barki-Harrington L, Wagner S: DNA methylation of specific CpG sites in the promoter region regulates the transcription of the mouse oxytocin receptor. PLoS One 2013;8:e56869.

28 Unternaehrer E, Luers P, Mill J, Dempster E, Meyer AH, Staehli S, Lieb R, Hellhammer DH, Meinlschmidt G: Dynamic changes in DNA methylation of stress-associated genes (OXTR, BDNF) after acute psychosocial stress. Transl Psychiatry 2012;2:e150.

29 Ziegler C, Dannlowski U, Brauer D, Stevens S, Laeger I, Wittmann H, Kugel H, Dobel C, Hurlemann R, Reif A, Lesch KP, Heindel W, Kirschbaum C, Arolt V, Gerlach AL, Hoyer J, Deckert J, Zwanzger P, Domschke K: Oxytocin receptor gene methylation: converging multilevel evidence for a role in social anxiety. Neuropsychopharmacology 2015;40:1528-1538.

30 Kumsta R, Hummel E, Chen FS, Heinrichs M: Epigenetic regulation of the oxytocin receptor gene: implications for behavioral neuroscience. Front Neurosci 2013;7:83.

31 Puglia MH, Lillard TS, Morris JP, Connelly JJ: Epigenetic modification of the oxytocin receptor gene influences the perception of anger and fear in the human brain. Proc Natl Acad Sci USA 2015;112:3308-3313.

32 Jack A, Connelly JJ, Morris JP: DNA methylation of the oxytocin receptor gene predicts neural response to ambiguous social stimuli. Front Hum Neurosci 2012;6:280.

33 Kusui C, Kimura T, Ogita K, Nakamura $H$, Matsumura Y, Koyama M, Azuma C, Murata Y: DNA methylation of the human oxytocin receptor gene promoter regulates tissue-specific gene suppression. Biochem Biophys Res Commun 2001;289:681-686.

34 Tost J, Dunker J, Gut IG: Analysis and quantification of multiple methylation variable positions in $\mathrm{CpG}$ islands by pyrosequencing. Biotechniques 2003;35:152-156.

35 Goodrich JM, Sanchez BN, Dolinoy DC, Zhang Z, Hernandez-Avila M, Hu H, Peterson KE, Tellez-Rojo MM: Quality control and statistical modeling for environmental epigenetics: a study on in utero lead exposure and DNA methylation at birth. Epigenetics 2015;10:19-30.
36 Keefe R: Brief Assessment of Cognition in Schizophrenia (BACS). Durham, Duke University Medical Center, 1999.

37 Keefe RS, Goldberg TE, Harvey PD, Gold JM, Poe MP, Coughenour L: The Brief Assessment of Cognition in Schizophrenia: reliability, sensitivity, and comparison with a standard neurocognitive battery. Schizophr Res 2004;68:283-297.

38 Grove T, Taylor S, Dalack G, Ellingrod V: Endothelial function, folate pharmacogenomics, and neurocognition in psychotic disorders. Schizophr Res 2015;164:115-121.

39 Vreeker A, Boks MP, Abramovic L, Verkooijen $S$, et al: High educational performance is a distinctive feature of bipolar disorder: a study on cognition in bipolar disorder, schizophrenia patients, relatives and controls. Psychol Med 2016;46:807-818.

40 Vargas G, Strassnig M, Sabbag S, Gould F, Durand D, Stone L, Patterson TL, Harvey PD: The course of vocational functioning in patients with schizophrenia: re-examining social drift. Schizophr Res Cogn 2014;1:e41e46.

41 Roth TL, Lubin FD, Sodhi M, Kleinman JE: Epigenetic mechanisms in schizophrenia. Biochim Biophys Acta 2009;1790:869-877.

42 Grayson DR, Guidotti A: The dynamics of DNA methylation in schizophrenia and related psychiatric disorders. Neuropsychopharmacology 2013;38:138-166.

43 Boyadjieva N, Varadinova M: Epigenetics of psychoactive drugs. J Pharm Pharmacol 2012; 64:1349-1358.

44 Benjamini Y, Hochberg Y: On the adaptive control of the False Discovery Rate in multiple testing with independent statistics. J Educ Behav Stat 2000;25:60-83.

45 Pike N: Using false discovery rates for multiple comparisons in ecology and evolution. Methods Ecol Evol 2011;2:278-282.

46 Glickman ME, Rao SR, Schultz MR: False discovery rate control is a recommended alternative to Bonferroni-type adjustments in health studies. J Clin Epidemiol 2014;67:850-857.

47 Chagnon YC, Potvin O, Hudon C, Preville M: DNA methylation and single nucleotide variants in the brain-derived neurotrophic factor (BDNF) and oxytocin receptor (OXTR) genes are associated with anxiety/depression in older women. Front Genet 2015;6:230.

48 Reiner I, Van IMH, Bakermans-Kranenburg MJ, Bleich S, Beutel M, Frieling H: Methylation of the oxytocin receptor gene in clinically depressed patients compared to controls: the role of OXTR rs53576 genotype. J Psychiatr Res 2015;65:9-15.

49 Kim YR, Kim JH, Kim MJ, Treasure J: Differential methylation of the oxytocin receptor gene in patients with anorexia nervosa: a pilot study. PLoS One 2014;9:e88673.
50 Gregory SG, Connelly JJ, Towers AJ, Johnson J, Biscocho D, Markunas CA, Lintas C, Abramson RK, Wright HH, Ellis P, Langford CF, Worley G, Delong GR, Murphy SK, Cuccaro ML, Persico A, Pericak-Vance MA: Genomic and epigenetic evidence for oxytocin receptor deficiency in autism. BMC Med 2009;7:62.

51 Schizophrenia Working Group of the Psychiatric Genomics Consortium: Biological insights from 108 schizophrenia-associated genetic loci. Nature 2014;511:421-427.

52 Haram M, Tesli M, Bettella F, Djurovic S, Andreassen OA, Melle I: Association between genetic variation in the oxytocin receptor gene and emotional withdrawal, but not between oxytocin pathway genes and diagnosis in psychotic disorders. Front Hum Neurosci 2015;9:9.

53 Feifel D: Oxytocin as a potential therapeutic target for schizophrenia and other neuropsychiatric conditions. Neuropsychopharmacol Rev 2012;37:304-305.

54 Ridderinkhof KR, Nieuwenhuis S, Braver TS Medial frontal cortex function: an introduction and overview. Cogn Affect Behav Neurosci 2007;7:261-265.

55 Leuner B, Gould E: Structural plasticity and hippocampal function. Annu Rev Psychol 2010;61:111-140, C111-C113.

56 Rich ME, Caldwell HK: A role for oxytocin in the etiology and treatment of schizophrenia. Front Endocrinol (Lausanne) 2015;6:90.

57 Owen AM: The functional organization of working memory processes within human lateral frontal cortex: the contribution of functional neuroimaging. Eur J Neurosci 1997;9:1329-1339.

58 Honey GD, Fu CHY, Kim J, Brammer MJ, Croudace TJ, Suckling J, Pich EM, Williams SCR, Bullmore ET: Effects of verbal working memory load on corticocortical connectivity modeled by path analysis of functional magnetic resonance imaging data. Neuroimage 2002;17:573-582.

59 Kondo H, Osaka N, Osaka M: Cooperation of the anterior cingulate cortex and dorsolateral prefrontal cortex for attention shifting. Neuroimage 2004;23:670-679.

60 Osaka N, Osaka M, Kondo H, Morishita M, Fukuyama H, Shibasaki H: The neural basis of executive function in working memory: an fMRI study based on individual differences. Neuroimage 2004;21:623-631.

61 Alvarez JA, Emory E: Executive function and the frontal lobes: a meta-analytic review. Neuropsychol Rev 2006;16:17-42.

62 Depp CA, Bowie CR, Mausbach BT, Wolyniec P, Thornquist MH, Luke JR, McGrath JA, Pulver AE, Patterson TL, Harvey PD: Current smoking is associated with worse cognitive and adaptive functioning in serious mental illness. Acta Psychiatr Scand 2015;131:333341 
63 Smith RC, Singh A, Infante M, Khandat A, Kloos A: Effects of cigarette smoking and nicotine nasal spray on psychiatric symptoms and cognition in schizophrenia. Neuropsychopharmacology 2002;27:479-497.

64 Mackowick KM, Barr MS, Wing VC, Rabin RA, Ouellet-Plamondon C, George TP: Neurocognitive endophenotypes in schizophrenia: modulation by nicotinic receptor systems. Prog Neuropsychopharmacol Biol Psychiatry 2014;52:79-85.

65 Burghardt KJ, Goodrich JM, Dolinoy DC, Ellingrod VL: DNA methylation, insulin resistance and second-generation antipsychotics in bipolar disorder. Epigenomics 2015;7:343352.

66 Maccani JZ, Maccani MA: Altered placental DNA methylation patterns associated with maternal smoking: current perspectives. Adv Genomics Genet 2015;2015:205-214.

67 Zhang Y, Schottker B, Florath I, Stock C, Butterbach K, Holleczek B, Mons U, Brenner H: Smoking-associated DNA methylation biomarkers and their predictive value for allcause and cardiovascular mortality. Environ Health Perspect 2016;124:67-74.

68 Kanamori C, Yasuda K, Sumi G, Kimura Y, Tsuzuki T, Cho H, Okada H, Kanzaki H: Effect of cigarette smoking on mRNA and protein levels of oxytocin receptor and on contractile sensitivity of uterine myometrium to oxytocin in pregnant women. Eur J Obstet Gynecol Reprod Biol 2014;178:142-147.

69 Novak V, Hajjar I: The relationship between blood pressure and cognitive function. Nat Rev Cardiol 2010;7:686-698.

70 Wadley VG, McClure LA, Howard VJ, Unverzagt FW, Go RC, Moy CS, Crowther MR, Gomez CR, Howard G: Cognitive status, stroke symptom reports, and modifiable risk factors among individuals with no diagnosis of stroke or transient ischemic attack in the REasons for Geographic and Racial Differences in Stroke (REGARDS) Study. Stroke 2007;38:1143-1147.
71 Crichton GE, Elias MF, Davey A, Alkerwi A: Cardiovascular health and cognitive function: the Maine-Syracuse Longitudinal Study. PLoS One 2014;9:e89317.

72 Imamura A, Takahashi R, Murakami R, Kataoka H, Cheng XW, Numaguchi Y, Murohara $\mathrm{T}$, Okumura K: The effects of endothelial nitric oxide synthase gene polymorphisms on endothelial function and metabolic risk factors in healthy subjects: the significance of plasma adiponectin levels. Eur J Endocrinol 2008;158:189-195.

73 Ellingrod VL, Taylor SF, Brook RD, Evans SJ, Zollner SK, Grove TB, Gardner KM, Bly MJ, Pop-Busui R, Dalack G: Dietary, lifestyle and pharmacogenetic factors associated with arteriole endothelial-dependent vasodilatation in schizophrenia patients treated with atypical antipsychotics (AAPs). Schizophr Res 2011; 130:20-26.

74 Burghardt K, Grove T, Ellingrod V: Endothelial nitric oxide synthetase genetic variants, metabolic syndrome and endothelial function in schizophrenia. J Psychopharmacol 2014; 28:349-356.

75 Dadds MR, Moul C, Cauchi A, Dobson-Stone C, Hawes DJ, Brennan J, Ebstein RE: Methylation of the oxytocin receptor gene and oxytocin blood levels in the development of psychopathy. Dev Psychopathol 2014;26:33-40.

76 Horvath S, Zhang Y, Langfelder P, Kahn RS, Boks MP, van Eijk $\mathrm{K}$, van den Berg $\mathrm{LH}$, Ophoff RA: Aging effects on DNA methylation modules in human brain and blood tissue. Genome Biol 2012;13:R97.

77 Thompson TM, Sharfi D, Lee M, Yrigollen CM, Naumova OY, Grigorenko EL: Comparison of whole-genome DNA methylation patterns in whole blood, saliva, and lymphoblastoid cell lines. Behav Genet 2013;43:168-176.
78 Beery AK, McEwen LM, MacIsaac JL, Francis DD, Kobor MS: Natural variation in maternal care and cross-tissue patterns of oxytocin receptor gene methylation in rats. Horm Behav 2016;77:42-52.

79 Ebstein RP, Knafo A, Mankuta D, Chew SH, Lai PS: The contributions of oxytocin and vasopressin pathway genes to human behavior. Horm Behav 2012;61:359-379.

80 Rajagopal L, Massey BW, Huang M, Oyamada Y, Meltzer HY: The novel object recognition test in rodents in relation to cognitive impairment in schizophrenia. Curr Pharm Des 2014;20:5104-5114.

81 Davies MN, Volta M, Pidsley R, Lunnon K, Dixit A, Lovestone S, Coarfa C, Harris RA, Milosavljevic A, Troakes C, Al-Sarraj S, Dobson R, Schalkwyk LC, Mill J: Functional annotation of the human brain methylome identifies tissue-specific epigenetic variation across brain and blood. Genome Biol 2012; 13:R43.

82 Provencal N, Suderman MJ, Guillemin C, Massart R, Ruggiero A, Wang D, Bennett AJ, Pierre PJ, Friedman DP, Cote SM, Hallett M, Tremblay RE, Suomi SJ, Szyf M: The signature of maternal rearing in the methylome in rhesus macaque prefrontal cortex and T cells. J Neurosci 2012;32:15626-15642.

83 Ursini G, Bollati V, Fazio L, Porcelli A, Iacovelli L, Catalani A, Sinibaldi L, Gelao B, Romano R, Rampino A, Taurisano P, Mancini M, Di Giorgio A, Popolizio T, Baccarelli A, De Blasi A, Blasi G, Bertolino A: Stress-related methylation of the catechol-O-methyltransferase $\mathrm{Val}^{158}$ allele predicts human prefrontal cognition and activity. J Neurosci 2011;31: 6692-6698.

84 Domschke K, Tidow N, Kuithan H, Schwarte K, Klauke B, Ambree O, Reif A, Schmidt H, Arolt V, Kersting A, Zwanzger P, Deckert J: Monoamine oxidase A gene DNA hypomethylation - a risk factor for panic disorder? Int $J$ Neuropsychopharmacol 2012;15:1217-1228. 